\title{
De la colaboración con el Estado a la protesta regionalista: la Junta de Minería de Copiapó desde las Reformas Borbónicas hasta la Guerra Civil de 1859
}

\author{
Joaquín Fernández Abara ${ }^{1}$ \\ Recibido: 20 de agosto de 2014 - Aceptado: 25 de septiembre de 2014
}

\begin{abstract}
Resumen
El artículo sigue la trayectoria de la Junta de Minería de Copiapó y su relación con el Estado. Sostiene que en el período tardocolonial y a inicios del republicano, el gobierno de las zonas mineras de Copiapó requirió del apoyo de los mineros agremiados. Las autoridades fomentaron la agremiación de los mineros en la Junta de Minería, a la que delegaron funciones administrativas y dieron amplia autonomía. Sin embargo, los gobiernos republicanos no formalizaron dicha institución, la que se mantuvo regida por la costumbre. Los intentos de controlar la administración y los recursos de la Junta, realizados a mediados de la década de 1850 por los agentes del Ejecutivo, cambiaron dicha relación, transformando a la Junta en un importante foco de conflictividad regionalista y abriendo un debate sobre su composición social.
\end{abstract}

Palabras clave:Minería, Centralización, Construcción de Estado, Conflictividad Regionalista.

\section{From collaboration with the state to regional protest: The Junta de Minería of Copiapó from Bourbon Reforms to the civil war in 1859}

\begin{abstract}
The article studies the Junta de Minería of Copiapó and its relationship with the State. It argues that in the late colonial and early republican period, the government of Copiapo mining areas required support from the unionized miners. The authorities encouraged unionization of miners delegating them administrative functions with a wide autonomy. However, Republicans governments did not formalize this institution which remained governed by custom.
\end{abstract}

Chileno. Magíster en Historia, Pontificia Universidad Católica de Chile. Académico e investigador, Centro de Investigación y Documentación en Chile Contemporáneo, Universidad Finis Terrae. E-mail: jfernandez@uft.cl 
The attempts to control the management and resources of the Board in the mid- 1850 s by agents of the Executive changed this relationship, turning the Board into a major focus of regionalist conflict and opening a discussion about its social composition.

Keywords: Mining, centralization, State building, regionalist conflict.

\title{
Da colaboração com o estado para o protesto regionalista: 0 Junta de Minería de Copiapó desde as reformas bourbonicas até a guerra civil de 1859
}

\begin{abstract}
Resumo:
0 artigo segue a trajetória do Conselho da Mineira de Copiapó e sua relação com o Estado. Argumenta que no período tardocolonial e no início do republicano, o governo dos setores mineiros de Copiapó precisou do apoio dos mineiros sindicalizados. As autoridades incentivaram a associação dos mineiros no Conselho mineiro, que delegou as funções administrativas e deu ampla autonomia. No entanto, os governos republicanos não formalizaram a instituição, que se manteve regida pelo costume. As tentativas de controlar a administração e os recursos do Conselho, realizado em meados da década de 1850 por agentes do Executivo, mudaram essa relação, transformando 0 Conselho num importante foco de tensão regionalista e abrindo um debate sobre sua composição social.
\end{abstract}

Palavras-chave: Mineira, Centralização, Construção do Estado, Conflito regionalista.

Tras los procesos independentistas, los Estados hispanoamericanos se encontraban en formación y buscaban generar gobernabilidad. Necesitaban crear una situación de estabilidad política que les permitiera ejecutar sus funciones con legitimidad, dando continuidad al nuevo orden republicano (Camou, 2000: 185). Sin embargo, su debilidad les impedía asumir por sí solos estos desafíos, problema que se volvía aún más dramático en las zonas periféricas o fronterizas. En estas condiciones, los representantes estatales debieron generar alianzas con diversos actores locales para hacer efectiva su capacidad de gobernar. Sin embargo, dicha situación fue en muchos casos traumática. A medida que los Estados quisieron expropiar funciones o controlar a estos actores locales con que habían pactado, generaron conflictos. Comunidades indígenas, cabildos y milicias, entre otras instituciones, eran algunos de los cuerpos del Antiguo Régimen que en determinados momentos fueron funcionales a los nuevos regímenes republicanos, pero que a la larga tuvieron conflictos de atribuciones con los Estados en formación y sus tendencias a la centralización. Así, los conflictos regionalistas del siglo XIX podrían explicarse en parte por la 
resistencia de estos grupos de identidades corporativas a renunciar a sus atribuciones y privilegios².

En el caso de Chile, las guerras civiles de la década de 1850 nos muestran la presencia de conflictos de este tipo, los que se hicieron especialmente notorios en las provincias del norte minero y en la frontera mapuche (Figueroa, 1889; Vitale, 1971; Zeitlin, 1984; Collier, 2005; Pinto, 2000).

El rápido fracaso de la experiencia federalista de 1826 y la elección de las élites políticas por un orden centralizado, han llevado a que en la historiografía chilena prevalezcan las visiones que desestiman los conflictos regionales. En cierto modo predomina una visión que resalta la excepcionalidad del caso chileno en el contexto latinoamericano ${ }^{3}$. Quizás dicha mirada implica una sobreestimación del poder del Estado, especialmente en los decenios pelucones -gobiernos conservadores que dominaron a Chile entre las décadas de 1830 y comienzos de la de 1860-. Esta postura queda claramente reflejada en la obra de Alberto Edwards, representante de la historiografía nacionalista-conservadora, quien describió a los gobiernos pelucones como administraciones fuertes, centralizadoras, impersonales y abstractas (Edwards, 1945). Cabe preguntarnos si era posible alcanzar dichos ideales en aquella época. Creemos que no. El propio Mario Góngora ha sostenido cómo la impersonalidad, valor propio de sociedades burguesas, no podía ser alcanzada en un contexto social de marcados tintes aristocráticos, como era el caso del Chile decimonónico (Góngora, 1981: 14-16). Al mismo tiempo, junto a estos juicios basados en el análisis de la estructura social, otros estudios más recientes han mostrado cómo la debilidad del Estado en el Chile pelucón llevó a que el gobierno tuviera que entrar en tácitas -y a veces explícitas- alianzas con las élites locales, buscando en estos "improvisados representantes" a los agentes capaces de poder mantener la administración y hacer viable la gobernabilidad local (Estefane, 2004). Así, las distintas ramas de la administración estatal, e incluso del poder militar, adquirieron la forma de un inconexo agregado de instituciones locales, que colaboró en la mantención de importantes grados de poder local (Fernández Abara, 2003).

En este artículo nos centraremos en el caso de Copiapó, ciudad que fue cabeza del levantamiento en armas de la provincia nortina de Atacama contra el "gobierno de Santiago" en el marco de la Guerra Civil de 1859. Analizaremos cómo el conflicto generado en torno a las atribuciones que debía tener la intendencia por sobre instancias de representación corporativa

Sobre estos actores corporativos, y su pervivencia en el orden postindependentista, véase Lomnitz (2001: 336-337), Guerra (1993: 323-327; 2000), Chiaramonte (2003) y De Gortari (2002).

3 Sobre la idea de la "excepcionalidad chilena", véase Blumenthal (2004). 
de los mineros de la localidad, produjo una fuerte tensión regionalista y fue uno de los factores que ayudaron a desencadenar la Guerra Civil.

Debemos recordar que hacia fines del siglo XVIII, la legislación minera borbónica incentivó la organización local de los mineros en instancias gremiales, a las que transfirió importantes atribuciones administrativas y judiciales. Con el advenimiento del orden republicano, y el auge de la minería de la plata en la provincia de Atacama en la década de 1830, los representantes del gobierno central revivieron dicha práctica. Así, fomentaron la agremiación de los mineros y la creación de una Junta de Minería que los representara en Copiapó. Los magnates mineros de la zona controlaron la institución y desarrollaron excelentes relaciones con las autoridades gubernamentales, las que permitieron que dicha Junta asumiera importantes funciones. Estas incluían la remuneración y organización de los cuerpos armados policiales y de las autoridades político-administrativas, judiciales y religiosas en los asientos mineros.

Al igual que en el período tardocolonial, la capacidad de los nuevos gobiernos republicanos para gobernar con efectividad en las zonas mineras requería del apoyo de los mineros agremiados. En este afán, el gobierno transformó a estos actores locales en sus agentes, pero no formalizó dicha situación: podía permitir amplios márgenes de autonomía a la Junta y encomendarle importantísimas tareas, sin embargo, entendía dicha delegación de funciones como un hecho de carácter temporal, basado en la costumbre. De hecho, prontamente, hacia mediados de la década de 1850 los Intendentes intervinieron la Junta controlando sus recursos y nombrando sus miembros.

Sin embargo, la reorganización de la Junta de Minería volvió a avivar una tradición corporativa que había creado la legislación minera dieciochesca. Los afanes centralistas del gobierno chocaron con ella y colaboraron en la génesis de un importante conflicto regionalista.

\section{El reformismo borbónico y la formación de los "gremios de minas" en Chile}

La legislación minera borbónica indujo y reforzó la agremiación, a la vez que fomentó el surgimiento de instancias de representación corporativas entre los mineros. En efecto, en el Chile colonial no existía una tradición de organización colectiva al interior del mundo de la minería. Como ha sostenido Luz María Méndez, los mineros chilenos trabajaban de manera "individual y apenas lograron conformar hacia mediados del siglo XVIII, pequeñas colectividades mineras que carecían de la más mínima organización gremial" (Méndez Beltrán, 1979: 26). 
Esta tendencia a la disgregación fue rota hacia fines del siglo XVIII, cuando la legislación minera de la Capitanía General de Chile fue reformada mediante la adopción de las Ordenanzas de Minería de Nueva España. La aplicación de las Ordenanzas implicaba la creación de un Tribunal de Minería, institución que debería hacerse cargo de la administración, la justicia y el fomento minero. Es importante resaltar que si bien la aparición de esta institución significaba la creación de un órgano administrativo central, al mismo tiempo alentaba la formación de un "gremio minero fuerte". En efecto, según las ordenanzas, los cargos del tribunal "eran electivos y sus componentes" debían ser "elegidos por representantes de los gremios mineros locales". Estos últimos representantes, conocidos como diputados territoriales, a su vez, debían ser elegidos en cada localidad (Méndez Beltrán, 1979: 30-34).

El impulso dado al gremio de minas se vio acompañado por un reforzamiento de su organización y poder en el ámbito local. Las ordenanzas establecían la formación de Diputaciones Territoriales en las localidades mineras. En ellas, los Diputados Territoriales, aparte de sus funciones representativas, tendrían atribuciones judiciales, administrativas y de fomento del ramo. Los diputados debían ser elegidos por una Junta de Mineros en enero de cada año, mediante votación, por el gremio local de minas (Méndez Beltrán, 1979: 49).

Por ello, cabe preguntarse quiénes podían formar parte del gremio de minas. Es necesario recordar que la legislación permitía que la composición social de dichos gremios fuese relativamente amplia, desbordando los márgenes elitarios. En su Título II, las ordenanzas establecían que para ser matriculado como minero "bastaba haber trabajado más de un año una o muchas minas, espendiendo como dueños de ellas en todo, o parte, su caudal o industria, o su personal diligencia o afán"4. Queda claro cómo incluso los dueños de pequeñas propiedades mineras podían hacerse parte del gremio. Esta situación, se daba en un contexto en que la posesión de las minas estaba abierta a cualquier individuo que "satisficiera los requisitos mínimos de denuncia, registro y explotación" (Salazar, 2000:178). Por lo demás, la legislación minera generaba tendencias a la proliferación de la pequeña propiedad, debido a que entregaba pertenencias "únicas" a cada descubridor, ponía cortapisas a la concentración de un gran número de pertenencias en manos de un solo descubridor y a la vez que estipulaba la división de la propiedad en fracciones, denominadas "barras", las que alcanzaban el número de veinticuatro (Venegas Valdebenito, 1989).

La legislación minera es un ejemplo interesante para comprender los mecanismos de acción utilizados por la administración colonial en sus afa-

4 Véase el Título $2^{\circ}$. Art. II (Reales Ordenanzas, 1783). 
nes reformistas durante el siglo XVIII. El impulso reformista borbónico se ha tendido a asociar a un incremento de la centralización administrativa ${ }^{5}$. Sin embargo, la legislación minera es un ejemplo de cómo sus efectos fueron contradictorios. En aras de llevar adelante una política de fomento y de poder hacer efectiva la administración, la justicia y la tributación en las zonas mineras, la administración colonial se esforzó en crear gremios, organizarlos y darles atribuciones administrativas y judiciales. La administración colonial requería del apoyo de los mineros para hacer efectiva la gobernabilidad local, organizándolos y delegando funciones con sus instituciones gremiales. En este proceso incluso fueron incorporados sectores ajenos a la elite $^{6}$.

Sin embargo, se vuelve necesario recordar que la adopción de la legislación minera novohispana en Chile fue paulatina. Así, durante el período tardocolonial podemos distinguir dos fases principales: la primera, que corresponde al período transcurrido entre los años 1787 y 1801, y la segunda entre los años 1802 y 1818. Durante la primera etapa, las ordenanzas mineras novohispanas comenzaron a aplicarse de manera parcial en Chile. En vez de un Tribunal de Minería, se instaló una Real Administración del Importante Cuerpo de Minería. A diferencia de su modelo mexicano, la institución chilena quedó estrictamente subordinada a la Superintendencia General Subdelegada de Real Hacienda. En el ámbito local, la institucionalidad minera fue adaptada a la Capitanía General de Chile según un modelo más centralizador. En efecto, no se llevaron adelante elecciones de Diputados Territoriales y, por lo mismo, las juntas y reuniones de mineros tuvieron un carácter eminentemente consultivo. Esta situación cambió con el advenimiento del siglo XIX, cuando durante una segunda etapa, se avanzó en una aplicación más ortodoxa de la legislación minera novohispana. En 1801, mediante una real orden, la Corona Española dispuso la adecuación de la Real Administración de Minería a su matriz mexicana, transformándose en Tribunal de Minería (Méndez, 1979: 29-45). Este cambio también implicó alteraciones locales. Así, se organizaron diputaciones territoriales, principalmente en la zona norte de la Capitanía General, donde se pretendía conformar las matrículas de mineros para realizar las elecciones de Diputados (Dougnac Rodríguez, 1999: 6-7).

Queda claro cómo la legislación minera tuvo en Chile un sesgo de carácter más bien centralista. Las instituciones mineras comprendidas en la Ordenanzas fueron, originalmente, adaptadas de tal manera que dependieran de órganos de la administración colonial. La conformación de las matrículas de mineros, y la realización de las elecciones, fueron procesos más bien lentos.

Es una de las tesis centrales de Lynch (1971). Véase también Brading (1971).

El uso de mecanismos de cooptación de las élites locales en el marco del reformismo borbónico ha sido tratado por Jocelyn-Holt (2001: 75-85) y por Barbier (1972). 
Los estudios existentes tienden a coincidir en que se trató de avances impulsados "desde arriba" por la administración colonial, ante mineros que tenían escasas tradiciones organizativas y no conocían las prácticas electorales ${ }^{7}$. Sin embargo, al finalizar la primera década del siglo XIX, ad portas de las guerras de independencia, las tendencias a la agremiación ya habrían arraigado en las diputaciones del norte de la Capitanía.

\section{La creación de una Junta de Minería en Copiapó}

Esta situación se hizo evidente en Copiapó. Al respecto, se hace necesario destacar que la aplicación de las ordenanzas y la política de fomento minero se llevaron a cabo en la zona de manera paulatina, y que las prácticas electorales nunca alcanzaron la regularidad que imponían las leyes. Sin embargo, las tendencias a la agremiación sí se hicieron patentes. Los mineros se agruparon en instituciones de carácter gremial y la posibilidad de interlocución con instituciones específicas para su actividad, los incentivó a articular sus demandas de manera colectiva.

En efecto, las políticas de fomento minero llevadas adelante por los gobernadores en el último cuarto del siglo XVIII, requerían del apoyo de la minería local. La ayuda de los mineros, como actores locales influyentes y conocedores de su zona, era fundamental para hacer viable la implementación de las políticas, al mismo tiempo que para generar un conocimiento sobre las potencialidades y problemas del territorio. Así, se desarrolló la práctica de las "visitas" de las altas autoridades de la administración colonial o sus enviados, quienes debían conocer las localidades de la capitanía y tomar contacto con los notables locales. En esta tendencia se enmarca la visita del Gobernador Ambrosio O'Higgins a los partidos del norte, que lo llevó a conocer el de Copiapó a fines del año 1788. En estas visitas, parte importante del tiempo estaba destinado a interiorizarse de los problemas de la zona y desarrollar medidas de fomento (Barros Arana, 2001: 18-25; Sagredo, 1999: 310-318, 2001: 167-171). En los partidos del norte, y especialmente en Copiapó, hubo una fuerte preocupación por los problemas de la minería (Sayago, 1973: 454).

La política de visitas fue clave para la organización de los mineros en Copiapó. Tras su visita a los partidos del norte, el Gobernador O'Higgins ordenó la realización de una visita general, con el fin de inspeccionar los trabajos mineros, labor que encomendó al Administrador General de Minería, Dr. Antonio Martínez de Matta. El administrador arribó a Copiapó en diciembre del año 1789. Luego de ponerse al tanto del estado de la industria minera

Véase, al respecto, el interesante estudio realizado por Cárcamo Siriguiado (2004). 
en la zona, procedió a reunir al gremio del partido. El fin de la reunión era interiorizar a los mineros en las nuevas ordenanzas. Sin embargo, al mismo tiempo, se proponía escuchar los reclamos de los mineros y sus sugerencias para el fomento del ramo (Álvarez Gómez, 1998: 47-49). Esta situación permitió a los mineros presentarse como grupo ante las autoridades, articulando petitorios de demandas de carácter general con aspiraciones viables de reconocimiento 8 .

Cabe cuestionarse qué clase de mineros eran los que se estaban juntando en torno a esta naciente identidad corporativa. Hay que destacar que nos encontramos ante una reunión de carácter elitista. En efecto, la reunión realizada bajo los auspicios de Martínez de Matta no agrupaba al gremio de minas en el sentido amplio que estipulaban las ordenanzas novohispanas. Por el contrario, se reunió a un total de treinta y tres mineros, un número extremadamente reducido de propietarios de minas para la zona. Se trataba de una reunión de notables, en que participaban miembros de la elite local que tenían calidad de vecinos, y en que tuvieron una fuerte predominancia algunos miembros de familias poderosas de la zona (Álvarez Gómez, 1998).

Además de la generación de vínculos de solidaridad colectiva en torno a aspiraciones comunes, la visita tuvo una proyección institucional de enorme trascendencia: la creación de una Junta de Minería en Copiapó. En efecto, se instaló una reunión de mineros notables que asumiría la representación corporativa del gremio de minas: el nuevo organismo se haría cargo de la superintendencia del ramo en el Partido, se encargaría del fomento minero, informaría sobre la situación de su actividad a las autoridades y se transformaría en un interlocutor válido ante ellas. La Junta debía estar compuesta de siete miembros, quienes a su vez deberían designar a sus sucesores para el año siguiente (Sayago, 1973: 456-457).

De este modo, se generó una situación de connivencia entre los intereses de las autoridades en Santiago y la élite minera local, que contrariaba las orientaciones generales dictadas por la legislación minera borbónica. Las autoridades coloniales en Santiago nombraban una junta de minería

Cabe destacar que ya en 1786, sólo dos años antes, los "mineros" locales habían logrado que, tras un litigio, se designara un "administrador de azogues", elegido por ellos, en despecho del designado originalmente por la Real Hacienda. Según el historiador Claudio Barrientos, se trata de una fuerte demostración de "poder local". Véase Barrientos Barría (1997). Dicha acción colectiva de los mineros, que llevó al nombramiento de una autoridad, contrasta con otras actuaciones anteriores sobre el problema del abastecimiento de azogue, fechadas por Barrientos en 1776 y 1739, en que los mineros se limitaron a hacer solicitudes puntuales a través de funcionarios de la administración colonial.

9 El caso extremo es el de la familia Mercado, que aportaba con cinco participantes, casi un sexto del total. 
entre los notables locales copiapinos, a la que autorizaban para autorreproducirse. Esto, a despecho de las ordenanzas mineras que apuntaban hacia la creación de gremios reunidos en torno a la propiedad minera, sin mayores barreras sociales de entrada y con elecciones abiertas. Dicha lógica persistió en el tiempo.

Incluso cuando comenzó a regularizarse la formación de Diputaciones Territoriales en la Capitanía en 1802, la institucionalidad minera local del Partido de Copiapó no se abrió a una agremiación masiva. En dicho año, el Diputado de Minas copiapino, Pedro de Fraga y Maquieira, señalaba al recién constituido Tribunal de Minería la necesidad de que "no se realicen elecciones" (Dougnac, 1999: 7). La postura homogeneizadora, que apuntaba a crear gremios amplios, triunfó temporalmente, y así en enero de 1803 el Tribunal de Minería dictaminó que "la junta de mineros, en voto secreto, tenía la facultad de nombrar al diputado de minas del partido". Sin embargo, menos de un año después, en noviembre de 1804, el Tribunal de Minería volvió a designar una Junta de Minería de entre notables locales, la que retomó las tendencias a la autorreproducción (Sayago, 1973: 459).

A lo largo de las dos primeras décadas del siglo XIX, la Junta de Minería continuó existiendo como un órgano de notables locales, que se autorreproducía, evitando las tendencias a una agremiación masiva. En los registros existentes entre los años 1804 y 1821, el predominio de conocidas familias de la elite local en el seno de la junta era indiscutible. Así, podría decirse que las familias Gallo, Mandiola, Ossa, Mercado, Goyenechea, Sierra y Sierralta, y -hacia el final- Matta, la controlaron sin mayores contrapesos (Sayago, 1973: 460-461) ${ }^{10}$.

\section{La Junta de Minería bajo el orden republicano y la agremiación informal de los mineros}

La existencia en Copiapó de una Junta de Minería, compuesta de notables mineros y con tendencia a la autorreproducción se perpetuó durante los primeros años del régimen republicano. Sin embargo, hacia comienzos de la década de 1820, en la misma época que los gobiernos independientes acometían al desmantelamiento de la institucionalidad minera borbónica, se pierden los rastros de la Junta copiapina.

10 Para conocer las familias notables de la elite local a fines del siglo XVIII y comienzos del XIX, junto al libro de Sayago -que nos permite distinguir a las familias que tenían vecindad al hacer la crónica del cabildo- recomendamos las referencias presentes en Álamos Concha (1995) y Fernández Chadwick (1993: 16-51). 
Pese a ello, de manera informal y esporádica, se mantuvo una tendencia a la agremiación, la que fue fomentada por las nuevas autoridades republicanas. Esto se debía, principalmente, al auge vivido por la minería en la zona tras el descubrimiento del mineral de Chañarcillo en 1832. En efecto, las autoridades locales nombradas por el gobierno central-los gobernadores del departamento de Copiapó, dependiente de la provincia de Coquimbo, y desde 1843, los intendentes de la nueva provincia de Atacama-fomentaron en diversas ocasiones el resurgimiento del "gremio de minas", para facilitar la mantención del orden público y la tributación en los asientos mineros. Se vuelve necesario recordar que el desarrollo minero transformó a la zona en un polo de atracción para grandes concentraciones de peones itinerantes y desarraigados, convirtiéndola en el foco de reiterados episodios de violencia social. El miedo a las asonadas peonales se transformó en un mal endémico del empresariado minero local (Illanes, 2010). En opinión de Bruno Zavala, cura párroco de Copiapó, en la zona con mucha "facilidad" se podía "improvisar una inmensa pueblada. Facilidad que proviene no sólo del genio característico de estas gentes, sino de que así los mineros como los aventureros no necesitan más que la manta y su cuchillo para atreverse con prontitud muchas leguas" (Zavala, 1855). Por lo tanto, la necesidad de crear instituciones para "pacificar" la zona y mantener el orden público se volvió apremiante. En este marco, la debilidad de los brazos locales del gobierno central -intendentes y gobernadores-, que apenas contaban con medios para mantener el orden público en los centros urbanos más grandes, se hizo patente. No es extraño que estas autoridades hayan convocado en reiteradas ocasiones al gremio de Minería: de esta manera, los agentes del Estado podían "externalizar" -temporalmente-sus funciones, asignándoselas a los empresarios interesados. Podemos notar esta situación a comienzos del año 1841, cuando el Gobernador del departamento de Copiapó incentivó la reunión del gremio de minas en varias ocasiones, para que nombrase comisiones que se encargasen de recaudar tributos de entre los mineros de los minerales de Chañarcillo, Pajonales y Algarrobito, para así poder proveer dichas zonas de tropas de gendarmes y un juez, además de crear reglamentos de policía. Las comisiones tendieron, casi invariablemente, a estar conformadas por miembros de las grandes familias de mineros de la zona (Gremio de Minería, 1841). Esta situación es el ejemplo de la tónica que tuvo la acción estatal en los asientos mineros en la década de 1840.

Al igual que en el período tardocolonial, aun a mediados del siglo XIX las autoridades del gobierno central necesitaban del apoyo de los mineros. De este modo los notables mineros locales de Copiapó se convirtieron, en la práctica, en verdaderos agentes del Estado: el gremio de minería continuó siendo un factor clave para la gobernabilidad local.

A medida que avanzaba esta última década, las tendencias a la agremiación de los mineros adquirieron más fuerza. En un comienzo fueron reto- 
madas como una iniciativa particular de los grandes mineros de la zona, con la tácita venia de la intendencia. De este modo, en abril de 1846 se instaló una autodenominada "Comisión Representativa del Gremio de Minería" del departamento de Copiapó. Se trató de una reunión privada a la que asistieron grandes mineros. Entre ellos miembros de las familias Ossa, Edwards y Gallo Goyenechea, que en ese momento ya eran grandes fortunas a nivel nacional. La Comisión decidió también encargarse de la administración de los fondos del gremio (Gremio de Minería, 1846a).

Junto con tomar providencias para la mantención del orden público, organizando y pagando a los policías en los asientos mineros, llegaron incluso a fijar el sueldo y pagar al subdelegado de Chañarcillo. Así se responsabilizaban de remunerar y, en cierto modo, controlar, a la autoridad gubernativa de esa zona minera. Del mismo modo, se encargaban de proponer a la intendencia los nombres de personas para ocupar dicho puesto. Fuera de estas funciones, asumieron la responsabilidad de la compostura de caminos en la zona (Gremio de Minería, 1846b).

La Junta obtuvo reconocimiento oficial en 1848, cuando en julio de dicho año más de cuarenta mineros se reunieron en la Sala Municipal de Copiapó por invitación del Intendente Manuel José Cerda. Los asistentes acordaron en forma unánime nombrar una comisión compuesta por siete secretarios y cuatro suplentes, la que se encargaría de representar los intereses del gremio. Esta "Comisión" o "Junta de Minería" recibió las facultades de "dar su opinión y hacer peticiones a las autoridades sobre todas las medidas que fueran convenientes adoptar en la protección de la minería", "formar los reglamentos necesarios para la buena administración de los minerales y aguadas", "Intervenir en la administración de los fondos pertenecientes a este ramo" y "representar en todo lo que fuese necesario a los dueños de las minas". Una vez creada, la comisión celebró su sesión de instalación el 20 de octubre del mismo año, en la que se acordó, por unanimidad, conceder su presidencia al Intendente de la Provincia, quien pasó a ser considerado -retomando la nomenclatura borbónica- como Diputado de Minas (Comisión de Minería, 1848). Así, se repetía la situación tardocolonial, en que un grupo de mineros, con un fuerte predominio de notables, se arrogó la representación del gremio local, en connivencia con las autoridades político-administrativas de la zona.

Si bien la Junta obtuvo un importante nivel de reconocimiento por parte de la Intendencia, no se hicieron esfuerzos serios por formalizar su situación. Se trataba de una institución que revivía por voluntad de los actores interesados y se normaba por la costumbre. Así, la composición del gremio, sus mecanismos de elecciones y su relación con la Intendencia no se explicitaron, a pesar de ser un ente colaborador con el Estado de suma importancia para la gobernabilidad local, que asumía varias de sus funciones ante su debilidad 
económica y lejanía ${ }^{11}$. El Estado en construcción podía recurrir a estas instancias, siempre que fueran de carácter informal, para subsanar sus falencias, pero no podía legalizarlas ni institucionalizarlas a riesgo de hipotecar, a mediano y largo plazo, sus atribuciones. Esta situación refleja la existencia de una distinción entre actores estatales y no estatales, y que la delegación de funciones en estos últimos era asumida como una situación circunstancial. De hecho los intentos realizados por la Junta para fijar, legalmente, impuestos para su financiamiento recaudados por ellos mismos, fueron rechazados por el Congreso. En dichas instancias se subió la tributación minera de la zona más de lo esperado por los mineros agremiados, la que además fue encauzada directamente al presupuesto nacional ${ }^{12}$.

Sin embargo, la relación de cooperación entre la Junta de Minería y el Gobierno Central se mantuvo hasta mediados de la década de 1850. En general, la Junta estuvo constituida por grandes magnates mineros y "vecinos respetables" vinculados a la propiedad minera en la región, y la intendencia continuó delegando en ella funciones de orden público, vialidad y pago de sacerdotes y funcionarios en los asientos mineros.

\section{Protesta regionalista, liberalismo y tradición corporativa}

Las relaciones entre la Junta de Minería y el Gobierno se volvieron conflictivas en la segunda mitad de la década de 1850. El contexto regional es clave para entender las pugnas que se desatarían en torno a la Junta. Se hace necesario recordar que la segunda mitad de la década de 1850 fue un período de fuerte agitación política en la provincia de Atacama, especialmente en sus departamentos norteños de Copiapó y Caldera, donde se desarrolló un movimiento opositor regionalista con una alta capacidad de movilización política. Las tensiones derivaron en el alzamiento de la provincia de Atacama, en el marco de la Guerra Civil de 1859, cuando la provincia rompió con el gobierno central y se declaró en rebeldía hasta que no se convocara una asamblea constituyente.

\footnotetext{
Según Venegas Valdebenito (1989) en el capítulo 2.2, "los particulares" debían "asumir la realización de actividades que el Estado es incapaz de llevar a cabo".

12 Venegas (1989) hace una interesante revisión de la evolución del sistema de tributación de la Junta. Nos muestra cómo desde 1848, ésta se cobró a través de la aduana departamental. En 1852, la Junta de Minería solicitaba gravar a un real cada marco de "metales fríos" de plata, es decir, de difícil beneficio. La recaudación debería ir en beneficio de la caja de la Junta de Minería. El gobierno no sólo rechazó la moción, sino que además dictó una ley que gravaba en un $5 \%$ a la exportación de los metales fríos.
} 
La agitación política se vio reforzada por serios problemas económicos. En la segunda mitad de la década de 1850, se vivió una crisis económica regional, debido a la baja en los precios y la disminución en las exportaciones de metales. Así, las exportaciones de plata a través del puerto de Caldera, que en el año 1855 habían alcanzado los \$3.829.490, disminuyeron en 1856 a $\$ 3.022 .595$, en 1857 fueron de 3.028 .595 y en 1858 de $\$ 2.309 .874^{13}$. En un contexto caracterizado por el agotamiento de los minerales de más alta ley y por la persistencia de una "economía de antiguo régimen" con escasos grados de inversión tecnológica, la consecuencia obvia fue el abandono de las minas de menor beneficio (Venegas Valdebenito, 2002; Ortega, 2005: 61-67). Los efectos sociales se hicieron sentir alcanzando tanto a parte importante del empresariado minero local como a los trabajadores. Relatos de memorialistas describen cómo antes de 1859 "las minas malas habían hecho que el pueblo de Copiapó estuviese lleno de huéspedes, que no tenían para vivir sino sus ahorros anteriores" (Carabantes, 1860: 73v). En este ambiente, la inseguridad se volvió parte del tono de vida. Relatos contemporáneos dejan testimonios de cómo los "vecinos respetables" temían a la "gente bruta que en número de dos o tres mil andaban sueltos y ociosos por la población" (Anónimo, 1859) ${ }^{14}$.

El viajero alemán Paul Treutler dejó en sus memorias un cuadro dramático sobre cómo cambió la vida de gran cantidad de propietarios mineros y comerciantes en Copiapó durante abril de 1855. La prisión por deudas se volvió un temor común en estos sectores sociales, a tal punto que, con algo de cinismo, la sección de la Cárcel de Copiapó destinada a los deudores pasó a ser llamada "Hotel Universo". Treutler (1958: 201-202) relata cómo:

"Hacía algunos meses que no visitaba Copiapó. Habían ocurrido, entre tanto, grandes cambios, no en cuanto a la edificación y el embellecimiento, pero sí en lo referente a los habitantes. Muchos de mis conocidos, que eran ricos cuando me había despedido de ellos la última vez, se encontraban ahora arruinados, por la decadencia de la minería de la plata, y poseían apenas los recursos indispensables para mantenerse ellos mismos y sus familias; no pocos de ellos se encontraban en la cárcel por deudas o habían huido del país. Varios dueños de minas habían perdido durante mi ausencia sus considerables fortunas en el juego, precipitándose ellos y los suyos en la miseria, por lo cual algunos se habían suicidado. Por su lado, no pocos comerciantes se

13 Véanse los anexos de A.N.A.I.A. Vol. 40.

14 En el Archivo Histórico Nacional de Santiago, la crónica aparece catalogada, erróneamente, como si fuera obra de José Nicolás Mujica. Probablemente se trató de un error de catalogación cometido antes de la década de 1890. 
habían declarado en quiebra, otros habían huido secretamente de Copiapó y varios estaban en la cárcel por deudas".

Junto a la crisis económica, la región comenzó a vivir una fuerte agitación política. Varias de las más importantes familias de magnates mineros, que hasta ese entonces se habían mostrado mayoritariamente proclives al Gobierno, comenzaron a pasar a la oposición, a la vez que importantes grupos de artesanos y pequeños mineros radicalizaron sus posturas políticas ${ }^{15}$. En las elecciones parlamentarias de 1855 la oposición liberal rompió el control gobiernista de la zona, pese a los intentos de intervención electoral llevados adelante por la intendencia. Manuel Antonio Matta, joven magnate minero local, y José Victorino Lastarria, conocido liberal santiaguino y mentor de la juventud rebelde influenciada por el 48 europeo, fueron electos diputados. En los cuatro años siguientes cristalizó en Copiapó, en forma paulatina, un importante movimiento opositor, en el que pueden diferenciarse dos vertientes principales, las que ya eran abiertamente distinguibles hacia mediados del año 1858. Existía una facción llamada "fusionista", por su adhesión a la Fusión Liberal-Conservadora, que incluía a algunas de las más importantes fortunas mineras de la zona, emparentadas entre sí, y muchas cuyas familias ya eran parte de la elite local a fines del período colonial, como era el caso de los Gallo, Matta y Carvallo. Dicho grupo, que llegó a ser llamado un "partido de familia", contaba con una importante red de dependientes en el mundo minero a través de sus administradores y mayordomos, a la vez que mediante los préstamos de "habilitación" controlaban a importantes grupos de pequeños empresarios mineros. En algunos casos, como el de la familia Gallo, habían militado en las filas del peluconismo hasta avanzada la década de 1850. Los fusionistas se encontraban plenamente insertos en los círculos de la alta política nacional y, en general, adherían a un liberalismo que pretendía controlar el autoritarismo presidencial. A esta oposición de elite se sumó otro círculo, cuyos miembros fueron llamados "liberales" a secas, "rojos" o "populares". Comandados por José Nicolás Mujica, director del diario El Copiapino, y por el ingeniero en minas Anselmo Carabantes,

15 Hacia las elecciones de 1855 las familias Matta, Carvallo y Mandiola habían pasado a la oposición. En las elecciones parlamentarias de 1858 se les sumó la familia Gallo. Los miembros de las familias Edwards y Ossa que se encontraban en Copiapó se mantuvieron leales al gobierno de Montt, aunque en el año 1858 tuvieron un bajo perfil político. Estas familias se constituían como verdaderos núcleos en torno a los cuales se tejían redes más amplias, las que les permitían hacer alianzas con otras familias de notables, tanto en Atacama como en el resto de Chile, a través de vínculos matrimoniales, económicos y amistad. Además podían movilizar a redes de dependientes gracias a su capacidad de crear lazos de clientelismo. Cabe destacar cómo los notables de estas familias seguían una suerte de "cursus honorum" político, partiendo por ocupar cargos municipales, para luego insertarse en la alta política nacional viajando a Santiago y ocupando puestos parlamentarios. Dos interesantes casos de estudio se encuentran en los artículos de Molina (2008) y Rubio (2008). 
intentaron ganar el apoyo de la pequeña minería y lograron un importante arraigo entre los artesanos de la ciudad de Copiapó. Su discurso derivó en un liberalismo radical de un tono más democratizante. En noviembre de 1858, elementos provenientes de ambos grupos formaron un "Club Constituyente"; se trataba de una agrupación política que seguía los moldes del club republicano francés. Sus objetivos públicos apuntaban a dar publicidad a la idea de reformar la constitución, llamando a una asamblea constituyente. De este modo adhería a los públicos llamados que los opositores liberales y ultramontanos hacían desde Santiago en aras de combatir las prácticas autoritarias del gobierno de Manuel Montt y sus conservadores autoritarios, también conocidos como Partido Nacional. Sin embargo, y también en coordinación con la oposición santiaguina, fraguaban un plan de levantamiento en contra del gobierno ${ }^{16}$.

En estas condiciones de crisis económica y agitación política, el discurso regionalista copiapino se exacerbó. Ya desde el siglo XVIII, el norte chileno se había consolidado como un espacio regional eminentemente minero (Carmagnani, 2001: 99-120). Sin embargo, tras el auge de la minería de la plata con los descubrimientos de Chañarcillo en 1832 y Tres Puntas en 1848, el dinamismo económico generó importantes cambios sociales, reforzando la atracción de corrientes migratorias que generaron una sensación de mayor dinamismo económico y movilidad social. No es de extrañar que estos fenómenos hayan tenido un correlato cultural en las representaciones que los nortinos y, especialmente, los copiapinos hacían de su región. La prensa copiapina estaba plagada de referencias que pretendían contraponer la imagen de un Copiapó tolerante, abierto a la inmigración extranjera, moderno y dinámico, a la de un Santiago y un Chile rural atrasados e intolerantes. La literatura costumbrista de José Joaquín Vallejo dejó testimonios de esta identidad modernizante:

"Es indudable que Copiapó no ha empezado de veras la carrera de los adelantamientos sino desde diez años a esta parte. La explotación de Chañarcillo, San Antonio y demás ricos minerales; la comunicación frecuente en que hemos entrado con otros pueblos y otros hombres, la inmigración de argentinos, y varias circunstancias de importancia han dado gran impulso a nuestra población, comercio, industria y cultura de costumbres; mejoras que hoy serían muy débiles, si se

16 Sobre la división de los partidos véanse las cartas de José María Silva Chávez, Intendente de Atacama, a Manuel Montt, del 4, 16 y 20 de abril de 1858. Informaciones sobre este mismo tema y la creación del Club Constituyente, se encuentran en casi todas la crónicas escritas por los revolucionarios con posterioridad a la revolución; estas se ubican en A.N.F.B.V.M. Vols. 47 y $47^{a}$. También véase Gazmuri (1992). 
hubiesen obtenido por efecto solo de nuestra revolución civilizadora" (Jotabeche, 1847: 223).

Esta suerte de regionalismo cultural e identitario fue adquiriendo rasgos políticos. La situación se volvió patente durante la segunda mitad de la década de 1850, cuando gran parte de la actividad de la oposición apuntó a criticar el excesivo poder de los agentes del gobierno central en la provincia. Los intendentes, caricaturizados como "sátrapas de la Persia" en la literatura liberal, fueron constantemente criticados. A la vez, se desconfió del control que estos podían ejercer sobre los cuerpos de policía, los que pasaron a ser vistos como una forma elegante de esconder ejércitos permanentes al servicio del Poder Ejecutivo (Barros Arana et al., 1861:113). Las pugnas tuvieron un momento álgido a fines de febrero de 1858 , cuando el Intendente Juan Vicente Mira mandó a flagelar a tres periodistas opositores, desatando fuertes movilizaciones en su contra, y obligándolo a renunciar (Vial, 1858).

Como forma de resistencia al poder del Ejecutivo y para poder preservar mayores grados de autonomía político-administrativa, las distintas ramas de la oposición reivindicaron la importancia de la autonomía de las corporaciones locales. En efecto, el regionalismo atacameño que movió a los participantes de la guerra de 1859 tuvo un marcado carácter corporativo. Ante la ausencia de una tradición arraigada de representación provincial, los municipios fueron enarbolados como las instituciones representativas de los intereses locales y como el contrapeso a las tendencias centralizadoras del Poder Ejecutivo. A lo largo del año 1858 los conflictos de atribuciones entre la Intendencia y los municipios de Copiapó y Caldera se volvieron recurrentes y pavimentaron el camino hacia la guerra.

Otra corporación local que fue reivindicada como depositaria de los intereses de la localidad y como forma de resistir el poder del gobierno fue la Junta de Minería. Debemos tener en cuenta, que en la década de 1850, la Junta de Minería elevó en reiteradas ocasiones representaciones solicitando la supresión de impuestos mineros en la zona, las que fueron rechazadas por el Gobierno Central (Junta de Minería, 1853). A comienzos del año 1855, por primera vez se enfrentaron una lista apoyada por la Intendencia contra otra que señalaba representar los intereses independientes de "los mineros". Ambas estaban encabezadas por magnates mineros, sin embargo, la lista opositora se presentó ante la elección con un discurso crítico de las autoridades salientes: su programa circuló por la ciudad el 31 de diciembre de 1854, en una hoja impresa en los talleres del diario local El Copiapino, titulada Mejoremos el personal administrativo. La lista también presentó un programa de acción titulado Programa de trabajos que ejecutará la junta que proponen los mineros. En el documento, la lista opositora defendía medidas de intervención del Estado para fomento de la minería en favor de los pequeños y medianos mineros. Principalmente apuntaba a aliviarlos ante 
el crónico problema de la falta de crédito, mediante préstamos estatales con intereses "razonables", rescatando implícitamente la tradición de los "bancos de avío". También defendía la necesidad de abastecer a los pequeños mineros de algunos insumos básicos en las faenas mineras, al mismo tiempo que insistían en "solicitar al gobierno la disminución de los derechos sobre las pastas y minerales, derechos que afligen en extremo al industrial en perjuicio del desarrollo de la industria" (El Copiapino, 1855) ${ }^{17}$. La elección se realizó en la Sala Municipal en la tarde del $1^{\circ}$ de enero, con una "numerosa concurrencia de mineros". Aunque el intendente intentó aplazar la elección postergándola un día fracasó en su cometido, obteniendo el triunfo la lista independiente encabezada por el joven magnate Pedro León Gallo. La amplia movilización electoral, reflejó una participación de sectores más amplios de la minería. Las tendencias a una agremiación masiva y las prácticas electorales competitivas se instauraban por primera vez de manera efectiva.

Sin embargo, esta situación cambió abruptamente en 1856, cuando el día dos de enero se reunieron en la sala de la Intendencia con solo algunos de los vocales de la nueva Junta. En dicha ocasión, el Intendente subrogante Juan Vicente Mira leyó el siguiente decreto:

"Se suprime como informal y peligrosa para los intereses mineros la práctica indebida de elegir a los miembros de la Junta de Minería por todos los individuos que quieran presentarse a nombrarlos" (Junta de Minería, 1856).

La Intendencia estaba interviniendo la Junta de Minería, y pasaba a nombrar sus miembros. Para tomar esta determinación, sostenía que no había "reglamento ni disposición alguna" que determinara la forma de elegir a los miembros de la institución, "ni las cualidades que deban tener los electores". Planteaba que dicha situación se prestaba habitualmente a excesos, permitiendo la admisión de individuos "sin título de ningún género y más calificativo que su dicho de ser minero", lo que en la práctica se habría traducido en la extensión del "derecho a sufragio a los vagos, los niños y cuantos quieran presentarse a ejercerlos titulándose mineros". Ante dicha situación, la Intendencia aclaraba que debía encargarse de que los fondos del Gremio de Minería fueran administrados "por personas que presten toda garantía de celo, probidad y diligencia", por lo que debía "evitar que de la informalidad con que se ha acostumbrado nombrar las juntas [... ] resulte una elección perjudicial para el gremio" (Junta de Minería, 1858).

Como vemos, el brazo provincial del Ejecutivo destacaba la importancia de la corporación local de mineros, sobre todo por el aporte de sus fondos a

17 Sobre estos tradicionales reclamos económicos regionalistas véase Volk (1993). 
la administración local. Sin embargo, pretendía anular su rol de organismo deliberativo, evitando cualquier oposición a las medidas del Gobierno. Los límites que se imponían a la intervención del Intendente estaban dados por el respeto a los notables locales, sector social en este caso definido principalmente por su influencia social, dada por la riqueza, y en parte por el prestigio de pertenecer a familias aristocráticas con una relativa antigüedad en la zona. De este modo, al intervenir las elecciones de la Junta, se procuraba colocar en los puestos de vocales a partidarios de la Intendencia, pero, a la vez, se respetaba la presencia de los notables por una suerte de derecho propio, aunque hubiesen adoptado actitudes disidentes. En el marco de un Estado débil, el proceso de centralización administrativa apuntaba a controlar las instituciones corporativas locales y sus recursos, no a reemplazarlas.

Sin embargo, dicho concepto de la administración chocaba con la complejidad social que había adquirido la provincia. En Atacama se había constituido una economía donde la pequeña y mediana propiedad minera tenía una presencia importante y visible. Ya desde tiempos tardocoloniales, la legislación minera tendía a crear las condiciones para la proliferación de pequeñas y medianas posesiones. En estas condiciones, el auge de la minería, con el consiguiente incremento de la inmigración, había aumentado la importancia de sectores extraelitarios, que podrían llegar a considerarse protomesocráticos, y que ciertamente tenían un nivel de alfabetización e ingresos que les permitían acceder a la ciudadanía ${ }^{18}$. En dicho ambiente, no era extraño que hombres de estos sectores, muchos de ellos pequeños comerciantes o profesionales liberales, tuvieran participación en sociedades de explotación minera.

Por lo mismo, la decisión de la Intendencia desató airadas protestas. Estas fueron encabezadas por el periódico El Copiapino, cuyos editores pretendían movilizar a los sectores excluidos por la Intendencia. El diario, dirigido por José Nicolás Mujica, publicista de origen santiaguino que era dueño de pequeñas propiedades mineras, había asumido una posición de franca oposición al gobierno y sus páginas destilaban un liberalismo de tintes plebeyos y antioligárquicos. El propio Mujica, al mismo tiempo, desarrolló fuertes vínculos con sectores artesanales y de la pequeña minería, construyendo clientelas

18 Mientras en Chile había un 17,3\% de hombres alfabetos, el departamento de Copiapó alcanzaba un $29,4 \%$. Véase el Gobierno de Chile (1858). Con respecto a la cifra de ciudadanos, en Copiapó había un elector por cada treinta y dos habitantes y en el puerto de Caldera había uno cada veintiún, cifra muy superior al total nacional, que era de un elector cada setenta y cinco habitantes (Gobierno de Chile, 1863:450). Según puede inferirse de un catastro realizado por la Intendencia, hacia 1854 había alrededor de doscientos hombres que figuraban encabezando sociedades propietarias de minas. Esta cifra no tiene en cuenta a un número mucho mayor de otros socios dueños de barras. Véase Intendencia de Atacama, 1854: 102-111. 
al amparar y defender a mineros procesados por deudas ${ }^{19}$. De este modo, formó un polo radical de oposición liberal, el que solo dos años después, hacia 1858, ya era reconocido por el nombre de "Popular" o "Rojo". No era extraño entonces, que el diario asumiera una postura combativa, proclive a los intereses de la pequeña minería, conjugándola con las ideas de la oposición liberal. En este esquema, los artículos condenatorios hacia la actitud del intendente fueron presentados como cartas firmadas por "Mineros" o "Liberales". El afán democratizante de El Copiapino se fundía con el reclamo autonomista. En su campaña de oposición a la medida del Intendente, pretendió defender los derechos de corporaciones que estaban legitimadas por el paso del tiempo y la anterior aquiescencia de la autoridad; a la vez que resaltó el derecho de todos los propietarios de minas a participar de la elección de sus representantes y el control de los recursos que provenían de sus impuestos.

“El desacertado paso dado últimamente por el Intendente Interino de la provincia, relativo a la supresión del derecho de elegibilidad de la Junta de Minería acordado a todo propietario de minas por el acto de formación de un gremio de mineros, realizado en otro tiempo bajo los auspicios de la autoridad, y sancionado, puede decirse, por una larga práctica, ha venido a agregar un caso más a esa serie de hechos arbitrarios que se están sucediendo sin interrupción entre nosotros desde algunos años a esta fecha" (El Copiapino, 1856b).

El alegato de El Copiapino recogía elementos propios de una tradición corporativa, como la legitimación de las instituciones locales por la costumbre, fundiéndolos con un liberalismo de carácter democratizante que promovía la inclusión de algunos sectores extraelitarios. Los reclamos de El Copiapino asociaron los intereses económicos de los pequeños mineros y la defensa política de las libertades locales. Así, al defender la autonomía de la Junta, también defendía algunas de las ya tradicionales protestas económicas de los mineros. Sobre este punto, es necesario destacar que los reclamos por mayor autonomía económica estaban asociados a un localismo de carácter corporativo. Según la protesta de El Copiapino la Junta de Minería, elegida por el conjunto de los propietarios mineros, debía administrar en forma

19 Es interesante analizar el modo en que Mujica constituyó sus liderazgos. Junto con reivindicar las demandas del artesanado y de los pequeños mineros a través de su periódico El Copiapino, prestó asistencia a pequeños empresarios mineros endeudados, convirtiéndose en "fiador de cárcel segura", es decir, alojando como presos en su casa a personas que de otro modo irían a prisión por sus deudas. Anselmo Carabantes, otro de los líderes de los liberales rojos o populares, también realizó este tipo de prácticas. Las fuentes revisadas nos muestran que estos personajes fueron mucho más proclives a prestar este tipo de asistencia que los opositores pertenecientes a familias notables y que los gobiernistas. Véase Archivo Nacional, Archivo Notarial de Copiapó, vols. 106-131. 
independiente una porción mayoritaria de las recaudaciones locales y debía canalizar las demandas económicas de los mineros. En este sentido, los impuestos pagados por los mineros pasaron a considerarse como una suerte de "erogación voluntaria", en cuya administración debía tener una participación decisiva el gremio de minas local (El Copiapino, 1856).

La polémica puede ser considerada como el efecto de la formación de una opinión pública local, compuesta por sectores ajenos a la elite, pero con acceso a la lectura, a la ciudadanía y, en muchos casos, a la propiedad minera. Los representantes de estos sectores, en el ámbito de la prensa y de los "clubes políticos", rescataron en su discurso elementos propios de una tradición corporativa de notables, que se había forjado en el siglo XVIII. Sin embargo la reinventaron, asociándolas a nociones de ciudadanía más abiertas y masivas. Esta situación, que se hacía en parte posible por el carácter informal de las instituciones corporativas de la minería copiapina, nos muestra la plasticidad del discurso liberal ${ }^{20}$.

Aunque el control de la Intendencia sobre la Junta de Minería se mantuvo hasta fines del año 1858, sus formas se moderaron. Así, se siguió evitando la realización de elecciones abiertas, aunque se respetó la opinión de algunos de los mineros prominentes, a quienes se intentó atraer más sutilmente a través de mecanismos de cooptación. A fines de 1856, la convocatoria a la elección se hizo mediante "invitación nominal" a ciertos "mineros respetables" residentes en la ciudad a participar en una reunión en la Sala Municipal de Copiapó (Junta de Minería, 1863). De este modo se rescataba la formalidad del acto electoral, pero se mantenía la tendencia a intervenir las corporaciones mediante el nombramiento de partidarios de la administración, restringiendo el margen de la oposición a un reducido grupo de notables locales cuyo derecho a participar no era cuestionado.

Así, a la elección de diciembre de 1856 asistieron veinte personas. El Intendente Mira, quien presidía la reunión, mantuvo sus argumentos del año anterior, justificando los mecanismos de elección, e insistiendo en que "la ausencia de una matrícula de mineros que individualice a los que componen el Gremio y tienen voz activa en sus deliberaciones", habría llevado a la relajación de los nombramientos de la Junta en los años anteriores. Según Mira, dicha situación lo habría obligado a intervenir la elección anterior, nombrando "doce de los miembros más respetables y competentes" de la ciudad. Sin embargo, en aras de buscar un nombramiento "más satisfactorio para el gremio", habría "invitado a todos los sujetos interesados en él", proponiéndoles "para vocales de la junta que debe funcionar el año entrante

20 Al respecto véanse las reflexiones de Annino (Inédito: 1999). 
los mismos sujetos que han funcionado en la que expira, con sólo la variación de cinco" (Gremio de Minería, 1856).

Las invitaciones nominales a mineros notables por parte de la Intendencia se mantuvieron en la elección de marzo del año 1858 (Junta de Minería, 1863). Sin embargo, en dicho año el crecimiento de la oposición copiapina se hizo manifiesto y la elección se efectuó apenas con siete asistentes. Desde las páginas de El Copiapino se ironizó sosteniendo que no había "nada más elocuente para probar la inmensa popularidad de que el señor Intendente goza entre nosotros" (El Copiapino, 1858a). A pesar de la intervención del Intendente y del bajo número de votantes que asistieron, la elección no estuvo exenta de contrariedades. Al parecer, durante la reunión "tres de los circunstantes", cuyos nombres no hemos podido averiguar, "hicieron presente que no se consideraban aptos para hacer la elección", alegando que "el Gremio en general" de minería debía ser convocado mediante una invitación pública hecha por la prensa. Los otros cuatro integrantes habrían guardado silencio, aprobando una lista propuesta por la Intendencia (EI Copiapino, 1858a).

Durante todo este período, los mecanismos de renovación de las juntas de minería fueron arduamente criticados por la oposición. Especial indignación causaba el que la junta saliente, nombrada por el Intendente, invitara discrecionalmente, mediante oficios privados, a los mineros que la Intendencia creía conveniente para participar en la elección (El Copiapino, 1858b). Estos "oficios", calificados como simples "esquelas" por la prensa opositora, fueron desacreditados por su carácter privado (El Copiapino, 1858b).

Se acusaba al Intendente Mira de haber transformado a la Junta de Minería en un "cuerpo indeliberativo, un simulacro de corporación, que autorice todo lo que el intendente quiera y rechace lo que le desagrade, aunque convenga a los intereses de la comunidad". En consecuencia, El Copiapino declaraba la nulidad de los mecanismos de elección de la junta, sosteniendo la necesidad de "hacerla popular" para que fuese válida, evitando que esta quedase circunscrita a un grupo de sujetos "elegidos para elegir". Sólo de este modo la Junta de Minería sería el producto del "voto independiente de una mayoría apta para el ejercicio de un derecho ya reconocido" (EI Copiapino, 1858b). La crítica de El Copiapino también acusó a la intendencia de actuar arbitrariamente al designar los representantes que manejarían los caudales que los mineros habrían erogado voluntariamente, defendiendo el principio de que "las sumas que el pueblo deposita en su poder sirvan para el mismo pueblo" (El Copiapino, 1857). No era extraño que desde las páginas de El Copiapino se mostrara a la Junta de Minería como una corporación local, nacida como una asociación voluntaria, y destinada a representar los intereses de todos los productores mineros en un sentido socialmente amplio (El Copiapino, 1858c). 
La situación sufrió un giro al finalizar 1858. La elección de la Junta de Minería realizada el 30 de diciembre de dicho año significó una vuelta a prácticas más masivas de elección (Junta de Minería, 1863). El nuevo Intendente, José María Silva Chávez, en un afán de pacificar los ánimos de la oposición y de evitar reclamos de intervencionismo, invitó "por el periódico oficial a una reunión general para el 30 de diciembre a las 12 del día a la sala municipal". Fuera de la convocatoria, intentó generar una mayoría proclive al gobierno, esforzándose especialmente en enviar esquelas a sujetos supuestamente adherentes de la administración. Sin embargo, quedó impotente ante la actuación de los opositores. En efecto, de los invitados por el Intendente no concurrieron más que cuatro. Por el contrario, Pedro León Gallo, acaudalado miembro de una de las familias más importantes de la zona, se presentó acompañado de veinte a veinticinco hombres, todos miembros del Club Constituyente, "partido" que agrupaba a la oposición compuesta por los liberales "populares" y por los conservadores disidentes del Gobierno. Como resultado de esta operación, los vocales elegidos para componer la nueva junta fueron, en una abrumadora mayoría, opositores al Gobierno. Cabe destacar cómo, a excepción de Blas Ossa y José Antonio Moreno, todo el resto de la Junta era parte del Club Constituyente y, solo seis días después, tomaron las armas para hacer estallar la Revolución Constituyente en Atacama.

Según el intendente Silva Chávez se trataba de "la Junta más ridícula" que podía tener Copiapó. Los juicios del intendente dicen relación con la composición que adquirió la nueva Junta de Minería, en la que adquirieron protagonismo personajes de oposición, muchos de ellos de los sectores más radicales, como Anselmo Carabantes y Nicolás Mujica. A la vez hacen alusión a la constitución social que adquirió la Junta; de hecho el intendente Silva Chávez sostuvo que "con excepción de los señores Ossa Varas, Gallo, Matta, Carballo y Moreno, todos los demás con excepción de uno o dos son moros de garitos que no tienen con qué vivir". En efecto, varios de los vocales electos habían encabezado pequeñas sociedades explotadoras, o tenían una participación secundaria en la minería o sus actividades asociadas.

Silva Chávez Informó a Manuel Montt que había pensado hacer salir de la sala a los votantes que él consideraba no calificados, sin embargo:

"Esto no habría producido más que un desagrado y material para hablar de tiranía, cuando con esta medida no podría ni empatar el sufragio, pues es tan grande la diferencia que tuve que resignarme a sufrir, que al haber previsto yo un caso semejante no habría hecho tal elección y habría dejado la junta de 58 para 59, pues no hay estatutos ni reglamento alguno, y todo se hace por costumbre" (Silva Chávez, 1859).

Seis días después estalló la Guerra Civil de 1859 y la provincia de Copiapó se declaraba "separada" del "gobierno de Santiago". La Guerra Civil tuvo 
un claro tinte descentralizador y transformó en sus banderas la reforma de la Constitución. Uno de los primeros actos de los líderes revolucionarios, junto con solicitar el apoyo de la corporación municipal, fue solicitar el apoyo del gremio de minas local.

En efecto, la ritualidad política seguida por los rebeldes copiapinos apuntó a reivindicar la importancia de las corporaciones locales. La Junta de Minería se reunió el 8 de enero, presidida por el Intendente revolucionario Pedro León Gallo. Tras darse por instalada la nueva corporación, sus vocales nombraron una comisión para que estudiara en sus libros y cajas los fondos existentes, y "facultó al intendente para "que invirtiera los fondos de la junta en aquellos ramos del servicio público que con preferencia lo reclamen" y dejó a su "arbitrio" el manejo de dichos fondos" (Junta de Minería, 1859). En efecto, si bien se cedían los fondos de la corporación al nuevo gobierno revolucionario, se justificaba esta acción transformándola en una cesión voluntaria de fondos que la Junta tenía derecho a administrar libremente. La cesión de los fondos fue descrita por parte de los revolucionarios como un "voto elocuente de confianza" de parte del "gremio de mineros" (Anónimo, 1859).

Estos actos reafirman la mixtura entre liberalismo y regionalismo, y a la vez resaltan el carácter corporativo que esta última corriente adquirió en el norte chileno en el siglo XIX. Sectores sociales extraelitarios, pero que eran parte del espacio público, reinterpretaron la tradición corporativa y la tiñeron de un liberalismo de corte democratizante. La Junta de Minería, institución que desde el último cuarto del siglo XVIII había sido un reducto de familias de magnates mineros y notables locales, fue vista como una contención a los afanes centralizadores del Ejecutivo y como un espacio representativo de amplios sectores del mundo minero.

\section{Referencias bibliográficas}

\section{Fuentes primarias}

\section{a. Documentales}

\section{Archivo Nacional. Archivo Intendencia de Atacama (A.N.A.I.A.)}

COMISIÓN DE MINERÍA (1848). Instalación de la Comisión de Minería. Copiapó: 20 de julio de 1848. A.N.A.I.A., Vol. 71.

GREMIO DE MINERÍA (1846a). Sesión del gremio de mineros. Copiapó: 3 de abril de 1846. A.N.A.I.A., Vol. 71.

GREMIO DE MINERÍA (1846b). Sesión del gremio de mineros. Copiapó: 17 de abril de 1846. A.N.A.I.A., Vol. 71. 
GREMIO DE MINERÍA (1841). Libro de Acuerdos del Gremio de Minería. Copiapó: 13 de enero de 1841 y 20 de enero de 1841. A.N.A.I.A., Vol. 13.

GREMIO DE MINERÍA (1856). Sesión del Gremio de Mineros. Copiapó: 14 de diciembre de 1856. A.N.A.I.A., Vol. 137.

JUNTA DE MINERÍA (1853). Sesión de la Junta de Minería. Copiapó: 4 de julio de de 1853. A.N.A.I.A., Vol. 137.

JUNTA DE MINERÍA (1856). Instalación de la Junta de Minería: Copiapó: 2 de enero de 1856. A.N.A.I.A., Vol. 137.

JUNTA DE MINERÍA (1859). Sesión de Instalación de la Junta de Minería. Copiapó, 8 de enero de 1859. A.N.A.I.A., Vol. 137.

JUNTA DE MINERÍA (1863). Al señor Presidente de la Junta de Minería. Copiapó: 10 de mayo de 1863. A.N.A.I.A., Vol. 92.

\section{Archivo Nacional. Archivo Notarial de Copiapó (A.N.A.N.C.)}

A.N.A.N.C. Vols. 106-131.

\section{Archivo Nacional. Fondo Benjamín Vicuña Mackenna (A.N.F.B.V.M.)}

ANÓNIMO (1859). Apuntes de la revolución del cinco de enero de 1859 realizada en Copiapó. A.N.F.B.V.M. Vol. 48,

CARABANTES, A. (1860) Apuntes para la Historia de la Constituyente escritos por el señor Anselmo de Carabantes y seis páginas en que se fija un plan para escribir dicha historia.

A.N.F.B.V.M. Vol. 48-A.

\section{Archivo Nacional. Fondo Fundación Manuel Montt (A.N.F.F.M.M.)}

SILVA CHÁVEZ, J. M. (1858). Carta a Manuel Montt. Copiapó: 20 de abril de 1838. Vol. XIV.

SILVA CHÁVEZ, J. M. (1859). Carta de José María Silva Chávez a Manuel Montt. Copiapó: $1^{\circ}$ de enero de 1859. A.N.F.F.M.M. Vol. XV.

ZAVALA, B. (1855). Carta de Bruno Zavala a Manuel Montt. Copiapó: 20 de junio de 1855. A.N.F.F.M.M. Vol. X.

\section{b. Leyes y decretos}

REALES ORDENANZAS (1783). Reales ordenanzas para la dirección, régimen y gobierno del importante Cuerpo de la Minería de Nueva España, y de su Real Tribunal General. De orden de su majestad. Madrid. 


\section{c. Periódicos}

EL COPIAPINO (1855). El Copiapino. 2 de enero de 1855.

EL COPIAPINO (1856). "Lo que estamos viendo", en El Copiapino, Copiapó: 3 de enero de 1856.

EL COPIAPINO (1856b). "Junta de Minería", en El Copiapino, Copiapó: 3 de enero de 1856.

EL COPIAPINO (1857). El Copiapino. Copiapó: 28 de marzo de 1857.

EL COPIAPINO (1858a). El Copiapino. Copiapó: 4 de enero de 1858.

EL COPIAPINO (1858b). El Copiapino. Copiapó: 2 de enero de 1858.

EL COPIAPINO (1858c). El Copiapino. Copiapó: 11 de enero de 1858.

\section{d. Impresos}

INTENDENCIA DE ATACAMA (1854). Memoria que el Intendente de la Provincia de Atacama presenta al Señor Ministro de Estado en el Departamento de Interior dando cuenta de todos los ramos de la administración. Copiapó: Imprenta del Copiapino, 1854.

GOBIERNO DE CHILE (1863). Anuario estadístico de la República de Chile. Santiago: Oficina Central de Estadística.

GOBIERNO DE CHILE (1858). Censo jeneral de la República de Chile. Levantado en abril de 1854. Santiago: Imprenta del Ferrocarril.

JOTABECHE (1847). ¡Quién te vio y quién te ve. En Jotabeche [José Joaquín VaIlejo] (Ed.). Jotabeche, colección de los artículos de Jotabeche, publicados en El Mercurio de Valparaíso, en El Semanario de Santiago y en El Copiapino, desde abril de 1841 hasta septiembre de 1847. Santiago: Imprenta Chilena. 223 p.

TREUTLER, P. (1958). Andanzas de un alemán en Chile. 1851-1863. Santiago: Editorial del Pacífico.

VIAL, R. (1858). Refutación al libelo publicado en La Serena por D. Juan Vicente Mira, en defensa del atentado cometido por él en Copiapó el 27 de febrero de 1858. Santiago: Imprenta del País.

\section{Fuentes Secundarias}

ÁlAMOS CONCHA, P. (1995). Candelaria Goyenechea de Gallo. Una mujer del Siglo XIX. Tesis para al optar grado de Licenciado en Historia. Santiago: Pontificia Universidad Católica de Chile.

ÁlVAREZ GÓMEZ, O. (1998). "Etapa pionera de la minería atacameña y sus organizaciones gremiales", en Ingeniería: Universidad de Atacama. 
ANNINO, A. El paradigma y la disputa. Notas para una genealogía de la cuestión liberal en México y América Hispánica. Inédito.

ANNINO, A. (1999). "Ciudadanía 'versus' gobernabilidad republicana en México. Los orígenes de un dilema", en Sábato, H. (Ed.). Ciudadanía política y formación de las naciones. Perspectivas históricas de América Latina (pp. 140-189). México: FCE.

BARBIER, J. (1972). "Elites and cadres in Bourbon Chile", en The Hispanic American Historical Review, (52), 3.

BARRIENTOS BARRÍA, C. J. (1997). "Minería y poder en el Norte Chico. La distribución del azogue en el partido de Copiapó", en Pinto, J. (Ed.). Episodios de historia minera. Santiago, Universidad de Santiago.

BARROS ARANA, D. (2001). Historia General de Chile. Tomo VII. Santiago: Centro de Investigaciones Barros Arana - DIBAM.

BARROS ARANA, D. et al. (1861). Cuadro histórico de la administración Montt, escrito según sus propios documentos. Valparaíso: Imprenta y Librería del Mercurio de Santos Tornero.

BLUMENTHAL, E. (2004). El mito de la excepcionalidad chilena: un proyecto de construcción identitaria. Tesis para optar al Grado de Licenciado en Historia. Santiago: Pontificia Universidad Católica de Chile.

BRADING, D. (1971). Miners and merchants in Bourbon México, 1763-1810. London: Cambridge University Press.

CAMOU, A. (2000). "La múltiple (in)gobernabilidad. Elementos para un análisis conceptual", en Revista Mexicana de Sociología, (6)24.

CÁRCAMO SIRIGUIADO, U. (2004). Mineros y minería en el Norte Chico: La transición. Desde la colonia a las primeras décadas de la república. Tesis para optar al grado de Magíster en Historia en la Mención en Historia de Chile. Santiago: Universidad de Chile.

CARMAGNANI, M. Los mecanismos de la vida económica en una sociedad coIonial. Chile. 1680-1830. Santiago: DIBAM.

CHIARAMONTE, J. C. (2003). "El federalismo argentino en la primera mitad del siglo XIX", en Carmagnani, M (Ed.). Federalismos latinoamericanos. México / Brasil / Argentina (pp. 81-132). México: FCE.

COLLIER, S. (2005). La construcción de una república. 1830-1865. Política e ideas. Santiago: Ediciones PUC.

DE GORTARI, H. (2002). "Los ayuntamientos en el gobierno y organización territorial de los estados de la Federación Mexicana: 1824-1827", en Jahrbuch für Geschichte Lateinamerikas , 39. 
DOUGNAC RODRÍGUEZ, A. (1999). "Proyección de las Ordenanzas de Minería de Nueva España en Chile (1787-1874)", en Revista de estudios histórico-jurídicos, 21.

EDWARDS, A. (1945). La Fronda Aristocrática en Chile. Santiago: Editorial del Pacífico.

ESTEFANE, A. (2004). " "Un alto en el camino para saber cuántos somos...". Los censos de población y la construcción de lealtades nacionales. Chile, siglo XIX", en Historia, $N^{\circ} 37$, I.

FERNÁNDEZ ABARA, J. (2003). "Los Orígenes de la Guardia Nacional y la Construcción del Ciudadano-Soldado: (Chile. 1823-1833)", en Mapocho. Revista de Humanidades, 56.

FERNÁNDEZ CHADWICK, P. (1993). Miguel Gallo Vergara. Una fortuna del Siglo XIX. Tesis para optar al grado de Licenciado en Historia. Santiago: Pontificia Universidad Católica de Chile.

FIGUEROA, P. P. (1889). Historia de la Revolución Constituyente (1858-1859): Escrita sobre documentos completamente inéditos. Santiago: Imprenta Victoria.

GAZMURI, C. (1992). "La influencia del club republicano francés en las formas de sociabilidad política chilena de la segunda mitad del siglo XIX", en Fundación Mario Góngora, Formas de Sociabilidad en Chile 1840-1940. Santiago: Síntesis.

GÓNGORA, M. (1981). Ensayo histórico sobre la noción de Estado en Chile en los siglos XIX y XX. Santiago: Ediciones la Ciudad.

GUERRA, F. (1993). Modernidad e Independencias: Ensayos Sobre las Revoluciones Hispánicas. México: Mapfre - FCE.

GUERRA, F. (2000). "La Identidad Republicana en la Época de la Independencia", en Sánchez, G. \& Wills, M. E. (Ed.) Museo, Memoria y Nación. Bogotá: Museo Nacional de Colombia.

ILLANES, M. A. (2003). "Azote, salario y ley. Disciplinamiento y rebeldía de la mano de obra en la minería de Atacama. 1817-1852", en lllanes, M. A. (Ed.). Chile des-centrado. Formación socio-cultural republicana y transición capitalista (1810-1910). LOM: Santiago.

JOCELYN-HOLT, A. La independencia de Chile. Tradición, modernización y mito. Santiago: Planeta, 2001.

LOMNITZ, C. (2001). "Nationalism as a practical system. Benedict Anderson's theory of nationalism from the vantage point of Spanish America", en Centeno, M. A \& López-Alvez, F (Eds.). The other Mirror: Grand theory through the lens of Latin America. Princeton: Princeton University Press.

LYNCH, J. (1986). Las revoluciones hispanoamericanas. 1808-1826. Barcelona: Ariel. 
MÉNDEZ BELTRÁN, L. M. (1979). Instituciones y problemas de la minería en Chile: 1787-1826. Santiago: Ediciones de la Universidad de Chile.

MOLINA, J. (2008). "La red familiar de los Gallo en Copiapó y su rol político en la primera mitad del siglo XIX", en Revista de Historia y Geografía, № 22.

ORTEGA, L. (2005). Chile en ruta al capitalismo. Cambio, euforia y depresión. 1850-1880. Santiago: LOM-DIBAM.

PINTO, J. (2000). La formación del Estado, la nación y el pueblo mapuche. De la inclusión a la exclusión. Santiago: Centro de Investigaciones Diego Barros Arana - DIBAM.

RUBIO, P. (2008). "¿De revolucionario a moderado? Manuel Antonio Matta y su influencia en la política chilena, 1859-1892", en Revista de Historia y Geografía, $N^{\circ} 22$.

SAGREDO, R. (1998). "Las visitas gubernamentales en Chile, 1788-1861", en Historia, No 31.

SAGREDO, R. (2001). Vapor al norte, tren al sur. El viaje presidencial como práctica politica en Chile. Siglo XIX. Santiago: Centro de Investigaciones Barros Arana DIBAM Dirección de Bibliotecas Archivos y Museos.

SALAZAR, G. (2000). Labradores, peones y proletarios. Formación y crisis de la sociedad popular chilena del siglo XIX. Santiago: LOM.

SAYAGO, C. M. (1973). Historia de Copiapó. Buenos Aires-Santiago: Editorial Francisco de Aguirre.

VENEGAS VALDEBENITO, H. (1989). Concertación empresarial y trabajadores mineros en una economía en transición, Copiapó 1848-1865. Tesis para optar al grado de Magíster Artium en la Mención en Historia. Santiago: Universidad de Santiago.

VENEGAS VALDEBENITO, H. (2002). "Minería y transformaciones sociales y demográficas durante el primer ciclo de expansión de la economía chilena. Atacama 1850-1880", en Contribuciones científicas y tecnológicas. Área Ciencias Sociales, 130.

VITALE, L. (1971). Las guerras civiles de 1851 y 1859 en Chile. Concepción: Universidad de Concepción.

VOLK, S. (1993). "Mine owners, moneylenders, and the State in mid-nineteenthcentury Chile: Transitions and conflicts", en Hispanic American Historical Review, $N^{\circ} 73$, l.

ZEITLIN, M. (1984). The civil wars in Chile (Or the burgeois revolutions that never were). Princeton: Princeton University Press. 